\title{
Revisiting the Apparent Paradox: Foreign Capital Inflow, Welfare Amelioration and 'Jobless Growth' with Agricultural Dualism and Non-traded Intermediate Input
}

\author{
Soumyatanu Mukherjee \\ University of Calcutta
}

\begin{abstract}
In order to answer the pertinent question why developing countries are showing penchant for foreign capital over the last two decades in spite of its detrimental effects as revealed from the conventional two-sector mobile capital version of Harris-Todaro (HT) model in the presence of protectionist policy; this paper, in terms of a three-sector HT type general equilibrium model with agricultural dualism where advanced agricultural sector produces a non-traded intermediate input using capital apart from labour and land for the agro-based industry in the urban sector, tries to show that foreign capital inflow may not only improve social welfare, but also lower the magnitude of urban unemployment of labour or may lead to the phenomenon of 'jobless growth'.
\end{abstract}

- JEL Classification: C62, C68, F16, F11, F21, J01, J21, O18

- Keywords: Foreign Capital, Agricultural Dualism, Non-traded Intermediate Input, Welfare, Urban Unemployment, Jobless Growth, Stolpersamuelson Theorem, General Equilibrium Model.

\footnotetext{
*Corresponding address: Soumyatanu Mukherjee; M.Sc. (Economics), Department of Economics, University of Calcutta, 56A, B.T. Road, Kolkata 700050, India. Tel: +913325576472 (R), +919434116277(Mobile). E-mail: soumyatanu.mukherjee@yahoo.com

(C)2012-Center for Economic Integration, Sejong Institution, Sejong University, All Rights Reserved.
} 


\section{Introduction}

In a two sector mobile capital Harris-Todaro (HT) model (Corden and Findlay 1975), an inflow of foreign capital with full repatriation of its earnings and tariff protection is not only welfare worsening (Brecher and Alejandro 1977), (Beladi and Marjit 1992a, 1992b), (Chandra and Khan 1993); but also aggravates the problem of urban unemployment (Khan 1980, 1982) in developing dual economies. Then why developing countries are hungry for foreign capital given the standard welfare deteriorating and unemployment accentuating effects of it ${ }^{1}$ ? I have made an attempt to find a satisfactory answer to the above question, including agricultural dualism and non-traded sector (the two salient features of a less developed economy) also in my model. ${ }^{2}$

In the context of the agriculture-dominated, 'labour-surplus' developing economies, the phenomenon of development in the presence of agricultural dualism (connoting the coexistence of an advanced agrarian sector with a 'precapitalist backward agriculture') has received prominence. Advanced and backward agriculture can be distinguished in terms of inputs used, economies of scale, efficiency and elasticity of substitution. In the backward agricultural sector of a developing economy, the farmers stick to primitive methods of cultivation while in other parts of the economy the introduction of the so called 'Green Revolution' technology brought about revolutionary changes with respect to production technologies and modern inputs use and the increase in factor productivity. But, this technology is limited only to a few parts of a developing economy and only rich (large) farmers can get benefit from it. The small and marginal farmers continue to depend on rain-fed backward agricultural technique. Therefore, the adoption of the Green Revolution technology has also intensified the extent of agricultural dualism in a developing economy.

The non-traded goods may be either intermediate inputs or final commodities.

\footnotetext{
${ }^{1}$ According to the World Development Report (1999), the amount of foreign direct investment (FDI) to the low income countries has increased from US\$ 1502 millions in 1980 to US\$ 9433 millions in 1996. The corresponding figures for South Asian countries are US\$ 464 and 3479 millions, respectively. Besides, as per the UNCTAD (1999) and Oxfam (2002) reports, foreign capital accounts for 11 percent of fixed capital investment (10 times the share in 1980), and almost one-third of that in the manufacturing sector.

${ }^{2}$ It should be mentioned that Molana and Montagna (2007) also examined welfare consequences of a small open economy with free trade in final goods and international capital mobility but with aggregate increasing returns to scale. Also one can see Gorg et al. (2009).
} 
Here we assume the advanced agricultural sector is producing a non-traded intermediate input for the urban sector. It may be pointed out that in the model of Chaudhuri (2007); the advanced agricultural sector produces a non-traded final good using only labour and land, whereas here we have assumed that the advanced agricultural sector consists of many subcontract firms producing commercial agricultural crops for the urban agro-based industrial sector, which is also absolutely relevant for developing economies. For example: agriculture sector provides sugarcane to sugar mills to convert it into sugar, the development of textile industry and its allied fields is entirely attributed to cotton producing subcontract agricultural firms. Such commodities are restricted to cross international borders by the domestic government mainly in order to:

a) control prices in the domestic market,

b) ensure sufficient supply of this vital input to the agro-based industry.

For example, India has put a restriction on cotton exports to 55 lakh bales this season for the above mentioned reasons.

The present paper shows that, in the setup of a three sector HT model with agricultural dualism where one sector produces non-traded commercial crop with the help of capital along with land and labour for the agro-based industrial sector, an inflow of foreign capital does not necessarily worsen welfare and aggravate the problem of urban unemployment in the developing countries. In particular, the present analysis justifies the desirability of foreign direct investment (FDI) in a developing economy from the view points of both welfare and unemployment problem and also explains the phenomenon of 'jobless growth' in the liberalized regime. This paper should be considered as an extension of Chaudhuri (2007) paper, which showed the same but using a non-traded final commodity; while in this paper the non-traded sector produces an intermediate input, using only labour and land in the production process.

\section{The Model}

We consider a small open dual economy, which is broadly divided into an urban manufacturing sector and a rural sector. The rural sector is further ramified into two sub sectors so that in all we have three sectors in our economy. Of the two rural sectors, there is a backward agricultural sector (sector 1) within the rural sector, which produces its output using labour and land as inputs. This is the export sector of the economy. Another sector is the advanced agricultural sector (sector 2) 
producing a commercial agricultural crop for sector 3 using land, labour and capital. Finally, sector 3 (urban sector) may be an agro-based industry that uses labour, capital and the commercial crop produced by sector 2 . Sector 3 is the import-competing sector of the economy and is protected by an import tariff. The per-unit requirement of the intermediate input is assumed to be technologically fixed in sector $3 .{ }^{3}$ Let us now assume that labor in sector 3 earns an institutionally given wage, $\mathrm{W}^{*},{ }^{4}$ while the wage rate in the other two sectors, $\mathrm{W}$, is market determined. So labor is perfectly mobile between sectors 1 and 2, but imperfectly mobile between sector 3 and the rest of the economy. Land (capital) is perfectly mobile between sector 1 (sector 3 ) and sector 2 . The capital stock of the economy includes both domestic and the foreign capital and these are perfectly substitutes. Production functions exhibit constant returns to scale with diminishing marginal productivity to each factor. The two wages are related by the Harris-Todaro (1970) condition of migration equilibrium where the expected urban wage equals the rural wage with $W>W^{*}$. Income from foreign capital is entirely repatriated back to the source country. Commodity 1 is chosen as numeraire.

The following symbols will be used in the formal presentation of our model.

$$
\begin{gathered}
W a_{L 1}+R a_{N 1}=1 \\
W a_{L 2}+R a_{N 2}+r a_{K 2}=P_{2} \\
W^{*} a_{L 3}+P_{2} a_{23}+r a_{K 3}=(1+t) P_{3}
\end{gathered}
$$

Where

$W=$ competitive wage rate in two agricultural sectors; $W^{*}=$ institutionally given wage rate in the agro-based industrial sector; $R=$ rate of return to land; $r=$ rate of return to capital (domestic and foreign); $a_{i j}=$ input coefficients;

Full utilization of land and capital would imply the following 2 Equations, respectively

\footnotetext{
${ }^{3}$ It rules out the possibility of substitution between the non-traded input and other factors of production in Sector 3.

${ }^{4}$ Assuming that each urban sector firm has a separate trade union, the unionized wage function may be derived as a solution to the Nash bargaining game between the representative firm and the representative union in the industry. This function has been derived in details in Chaudhuri (2003).
} 


$$
\begin{gathered}
a_{N 1} X_{1}+a_{N 2} X_{2}=N \\
a_{K 2} X_{2}+a_{K 3} X_{3}=K_{D}+K_{F}=K
\end{gathered}
$$

Where,

$L=$ fixed number of workers in the economy; $N=$ economy's given endowment of land

$K_{D}=$ domestic capital stock of the economy; $K_{F}=$ foreign capital stock of the economy;

$K=$ economy's aggregate capital-stock (domestic plus foreign).

There is unemployment of labour in the urban sector. The labour-endowment equation of the economy is given by the following:

$$
a_{L 1} X_{1}+a_{L 2} X_{2}+a_{L 3} X_{3}+L_{u}=L
$$

where,

$L_{U}=$ level of urban unemployment

$$
\left(\frac{W^{*}}{W}\right) a_{L 3} X_{3}+a_{L 2} X_{2}+a_{L 1} X_{1}=L
$$

The demand for non-traded input must equal its supply. So we have

$$
\begin{gathered}
X_{2}=X_{2}^{D}=a_{23} X_{3} \\
M=D_{3}\left(\underset{(+)}{P_{2}, P_{(-)}} P_{(+)}^{*}, Y\right)-X_{3}
\end{gathered}
$$

Where,

$M=$ import demand for commodity 3 .

The country's social welfare is measured by strictly quasi-concave social welfare function:

$$
V=V\left(D_{1}, D_{3}\right)
$$

Where,

$\mathrm{D}_{1}=$ domestic demand for commodity $1 /$ consumption of commodity 1 by the 
society.

$\mathrm{D}_{3}=$ domestic demand for commodity $3 /$ consumption of commodity 3 by the society. ${ }^{5}$

Economy's budget constraint is given by

$$
D_{1}+P_{3}^{*} D_{3}=W L+R N+r K_{D}-t P_{3}\left(D_{3}-X_{3}\right)
$$

The National Income at domestic prices

$$
Y=W L+R N+r K_{D}-t P_{3}\left(D_{3}-X_{3}\right)
$$

We have eight endogenous variables in the system: $W, R, r, P_{2}, X_{1}, X_{2}, X_{3}$ and $L_{U}$. The policy parameters are $t, W^{*}$ and $K$. It is not a decomposable system. We can solve $W, R$ and $r$ from Equations (1) to (3) as functions of $P_{2}$ since $W^{*}, P_{3}$ and $t$ are given exogenously. Once factor prices are determined, factor coefficients are also determined as functions of $P_{2}$. Then from Equations (4), (5) and (6.1), $X_{1}, X_{2}$ and $X_{3}$ are obtained and $P_{2}$ is found from Equation (8). Finally, $L_{U}$ is found from Equation (6). Thus the equilibrium values of all the endogenous variables are now obtained in terms of the parameters of the model.

\section{Comparative Static Exercise}

Differentiating Equations (6.1), (4) and (5) respectively, the following expressions can be obtained:

$$
\begin{gathered}
X_{2}=\left(\frac{1}{|\lambda|}\right)\left[\left(\lambda_{N 1} \lambda_{K 3} A_{1}+\lambda_{L 1} \lambda_{K 3} A_{2}+\tilde{\lambda}_{L 3} \lambda_{N 1} A_{3}\right) P_{2}+\tilde{\lambda}_{L 3} \lambda_{N 1} K\right] \\
X_{3}=\left(\frac{1}{|\lambda|}\right)\left[\left(\lambda_{L 1} \lambda_{N 2} A_{3}-\lambda_{L 1} \lambda_{K 2} A_{2}-\lambda_{L 2} \lambda_{N 1} A_{3}-\lambda_{N 1} \lambda_{K 2} A_{1}\right) P_{2}+\left(\lambda_{L 1} \lambda_{N 2}-\lambda_{L 2} \lambda_{N 1}\right) K\right]
\end{gathered}
$$

Differentiating Equation (8) and using Equations (12) and (13) and simplifying we obtain

$$
\hat{P}_{2}=-\left(\frac{\hat{K}}{\Delta}\right)\left(\lambda_{L 1} \lambda_{N 2}-\lambda_{L 2} \lambda_{N 1}-\tilde{\lambda}_{L 3} \lambda_{N 1}\right)
$$

${ }^{5}$ Demand for non-traded input is absent in the social welfare function for obvious reason. 
Where

$$
\Delta=\left[A_{3}\left(\lambda_{L 1} \lambda_{N 2}-\lambda_{L 2} \lambda_{N 1}-\tilde{\lambda}_{L 3} \lambda_{N 1}\right)-\lambda_{L 1} A_{2}-\lambda_{N 1} A_{1}\right]
$$

Finally, totally differentiating Equations (1), (2), (3); solving by Cramer's Rule and using Equation (16) and collecting terms, one can write:

$$
\begin{aligned}
& \hat{W}=\left(\frac{\theta_{N 1}}{|\theta|}\right)\left[\left(\theta_{K 3}+\theta_{23} \theta_{K 2}\right)\left(\frac{\hat{K}}{\Delta}\right)\left(\lambda_{L 1} \lambda_{N 2}-\lambda_{L 2} \lambda_{N 1}-\tilde{\lambda}_{L 3} \lambda_{N 1}\right)\right] \\
& \hat{R}=\left(\frac{\theta_{L 1}}{|\theta|}\right)\left[\left(\theta_{K 3}+\theta_{23} \theta_{K 2}\right)\left(\frac{\hat{K}}{\Delta}\right)\left(\lambda_{L 1} \lambda_{N 2}-\lambda_{L 2} \lambda_{N 1}-\tilde{\lambda}_{L 3} \lambda_{N 1}\right)\right] \\
& \hat{r}=\frac{\left(\theta_{L 1} \theta_{N 2}-\theta_{N 1} \theta_{L 2}\right)}{|\theta|} \theta_{23}\left[\left(\frac{\hat{K}}{\Delta}\right)\left(\lambda_{L 1} \lambda_{N 2}-\lambda_{L 2} \lambda_{N 1}-\tilde{\lambda}_{L 3} \lambda_{N 1}\right)\right]
\end{aligned}
$$

Where

$$
|\theta|=\theta_{K 3}\left(\theta_{L 1} \theta_{N 2}-\theta_{N 1} \theta_{L 2}\right)
$$

We assume that sector 2 is more labor-intensive than sector 1 . This is a legitimate assumption: Let us consider rice as produced in the backward agrarian sector (sector 1) and cotton (or jute) in the advanced agricultural sector (sector 2) for delivery to the textile industry. The production of rice requires less labor per unit of land vis-àvis the processing of raw cotton/jute for delivery to the textile industry. So, the output of sector 2 is relatively more labor-intensive compared to sector $1 .^{6}$ So, we have $|\theta|<0$.

Using the stability condition for equilibrium in the market for commodity 2, we find $\frac{\Delta}{|\lambda|}<0$.

Since, $\frac{\hat{r}}{\hat{K}}<0$ and we have $|\theta|<0,\left(\theta_{L 1} \theta_{N 2}-\theta_{N 1} \theta_{L 2}\right)<0 \Rightarrow \frac{\left(\lambda_{L 1} \lambda_{N 2}-\lambda_{L 2} \lambda_{N 1}-\tilde{\lambda}_{L 3} \lambda_{N 1}\right)}{\Delta}<0$ as sector 2 is more labor-intensive than sector 1 (which is relatively more landintensive); $\left(\lambda_{L 1} \lambda_{N 2}-\lambda_{L 2} \lambda_{N 1}-\tilde{\lambda}_{L 3} \lambda_{N 1}\right)$ is surely negative. Therefore, $\Delta$ must be positive. So, $|\lambda|<0$. So, from (14), it follows that $\hat{P}_{2}>0$ when $\hat{K}>0$. Now, from (16) and (17), we find that $\hat{W}>0$ and $\hat{R}<0$ when $\hat{K}>0$. This leads us to the following

${ }^{6}$ See Marjit (1991) for details. 
proposition.

Proposition 1: An inflow of foreign capital leads to-

(i) an increase in the rural wage rate;

(ii) a decrease in the return to land;

(iii) an increase in the price of the non-traded commercial crop- even when nontraded sector uses capital apart from labour and land.

We intuitively explain proposition 1 as follows. As the capital-stock of the economy rises, both the capital-using sectors (sector 2 and sector 3 ) expand due to the presence of complementarities between the two sectors. As a result, real return to capital (r) falls and that leads to a hike in $\mathrm{P}_{2}$ in order to satisfy the zero profit condition for sector 3. Therefore, by Stolper-Samuelson theorem, competitive rural wage rate $(\mathrm{W})$ increases and return to land $(\mathrm{R})$ falls. Also, as capital-labor ratio in both sector 2 and sector 3 will rise, producers of these two sectors are trying to substitute labor by capital. So in both these sectors, capital-output ratio rises and labor-output ratio falls. This creates a relative shortage of capital in both these sectors and as a result, because of the complementarities between these two sectors, both the sectors will contract. If the primary effect (expansion of both capital-using sectors) dominates this secondary effect, both of sectors 2 and 3 will expand.

Since only price of non-traded intermediate input is changing, we can measure the effect of foreign capital inflow on social welfare by changes in national income at domestic prices alone. An inflow of foreign capital with full repatriation of its earnings produces two effects on the welfare in this model. First, the competitive rural wage increases, but both the rental to land and the rate of return to domestic capital have decreased. So, the aggregate factor income rises (as the increase in aggregate wage income outweighs the decrease in the rental income to land and real capital earnings) and it produces a positive effect on welfare. Finally, an inflow of foreign capital leads to an increase in the domestic production of commodity 3 and therefore tends to lower the import demand. Thus, the cost of tariff protection of the supply side increases which works negatively on welfare. The net result of these two effects would be an increase in social welfare if the magnitude of the first positive effect would be stronger than the second effect. So, the following proposition now can be established.

Proposition 2: In an economy with a non-traded advanced agricultural sector 
and a tariff-protected import-competing sector, an inflow of foreign capital with full repatriation of its earnings may improve social welfare.

\section{A. Effect on urban unemployment:}

$$
\left(\frac{\hat{L}_{U}}{\hat{K}}\right)=-\left(\frac{W^{*}}{\left(W^{*}-\underset{(+)}{W}\left|\theta_{(-)}\right|_{(+)}\right.}\right)\left[\begin{array}{c}
\left\{\theta_{N 1}\left(\theta_{K 3}+\theta_{23} \theta_{K 2}\right)\right\}- \\
\left(\lambda_{L 1} \lambda_{N 2}-\lambda_{L 2} \lambda_{N 1}-\tilde{\lambda}_{L 3} \lambda_{N 1}\right) \\
\left(\frac{W^{*}-W}{W_{(+)}^{*}}\right)|\underset{(-)}{\mid(+)}| \Delta
\end{array}\right]
$$

From (23), it now follows that, $\mathrm{L}_{\mathrm{U}}<0$, when $\hat{K}>0$ if $\mathrm{G} \leq 0$, where $\mathrm{G}$ $=\left[\left\{\theta_{N 1}\left(\theta_{K 3}+\theta_{23} \theta_{K 2}\right)\right\}\left(\lambda_{L 1} \lambda_{N 2}-\lambda_{L 2} \lambda_{N 1}-\tilde{\lambda}_{L 3} \lambda_{N 1}\right)-\left(\frac{W^{*}-W}{W^{*}}\right)|\theta| \Delta\right]$. This leads to the final proposition of the model.

Proposition 4: An inflow of foreign capital lowers the level of urban unemployment if $\left[\left\{\theta_{N 1}\left(\theta_{K 3}+\theta_{23} \theta_{K 2}\right)\right\}\left(\lambda_{L 1} \lambda_{N 2}-\lambda_{L 2} \lambda_{N 1}-\tilde{\lambda}_{L 3} \lambda_{N 1}\right)-\left(\frac{W^{*}-W}{W^{*}}\right)|\theta| \Delta\right]<0$

Also, an FDI is not necessarily unemployment accentuating in a developing economy. It is quite possible that $\mathrm{G} \cong 0$. If this is the case, the country will experience a 'jobless growth'. In fact, many of the developing countries, including India, will experience such type of growth during the liberalized regime.

\section{Concluding Remarks}

In order to provide a possible answer to the most pertinent question over the last two decades, we have taken recourse to a three sector HT model with agricultural dualism and a non-traded intermediate input produced using capital apart from labour and land for the agro-based industry in the urban sector. We have seen that an inflow of foreign capital is likely to be welfare-improving and may not aggravate the problem of urban unemployment in this set-up.

This is because in the presence of agricultural dualism and a non-traded agricultural intermediate input, the aggregate factor income increases. This may outweigh the deadweight loss caused by the protectionist policy on the economy.

Also, the level of urban unemployment does not necessarily increase due to inflow of foreign capital. Therefore, this model has also demonstrated the existence of 'jobless growth' in many of the developing economies during liberalized 
regime.

Received 18 September 2011, Revised 22 October 2011, Accepted 30 October 2011

\section{References}

Beladi, H., Marjit, S. (1992a), "Foreign capital and protectionism”. Canadian Journal of Economics, 25, 233-238.

Beladi, H., Marjit, S. (1992b), "Foreign capital, unemployment and national welfare". Japan and the World Economy, 4, 311-317.

Brecher, R.A., Alejandro, C.F.D. (1977), "Tariffs, foreign capital and immeserizing growth". Journal of International Economics, 7, 317-322.

Chandra, V., Khan, M.A. (1993), "Foreign investment in the presence of an informal sector". Economica, 60, 79-103.

Chaudhuri, S. (2003), "How and how far to liberalize a developing country with informal sector and factor market distortions". Journal of International Trade and Economic Development, 12(4), 403-428.

Chaudhuri, S. (2007), "Foreign capital, welfare and urban unemployment in the presence of agricultural dualism”. Japan and the World Economy, 19 (2007), 149-165.

Corden, W.M., Findlay, R. (1975), "Urban unemployment, intersectoral capital mobility, and development policy in a dual economy". Economica, 42, 59-78.

Gorg, H., Molana, H., Montagna, C., January. (2009), "Foreign Direct Investment, Tax Competition and Social Expenditure". International Review of Economics and Finance, 18(1), 31-37.

Harris, J.R., Todaro, M. (1970), "Migration, unemployment, and development: a twosector analysis". American Economic Review, 60, 126-142.

Khan, M.A. (1980), "Dynamic stability, wage subsidies, and the generalized HarrisTodaro model". Pakistan Development Review, 19, 1-24.

Khan, M.A. (1982), "Tariffs, foreign capital and immeserizing growth with urban unemployment and specific factors of production". Journal of Development Economics, 10, 245-256.

Marjit, S., (1991), "Agro-based industry and rural-urban migration: a case for an urban employment subsidy", Journal of Development Economics, 35(2), 393-398.

Molana, Hassan, Montagna, Catia, December. (2007), "Expansionary Effects of The Welfare State in a Small Open Economy". The North American Journal of Economics and Finance, 18(3), 231-246.

Oxfam International. (2002), "Rigged Rules and Double Standards: Trade, Globalisation, and Fight against Poverty".

UNCTAD. (1999), Trade and Development Report 1999. United Nations, Geneva.

World Development Report. (1999), Oxford University Press for The World Bank. 


\section{Appendix}

$$
\begin{aligned}
& \bar{\lambda}_{L i} \bar{S}_{L j}^{k}=\left(\lambda_{L 1} S_{L N}^{1}+\lambda_{L 2} S_{L N}^{2}+\lambda_{L 2} S_{L K}^{2} \theta_{N 1}\right)>0 \\
& A_{2}=\left(\frac{1}{|\theta|}\right)\left[\left(\theta_{K 3}+\theta_{23} \theta_{K 2}\right) \bar{\lambda}_{L i} \bar{S}_{N j}^{k}+\theta_{23}\left(\theta_{L 1} \theta_{N 2}-\theta_{N 1} \theta_{L 2}\right) \lambda_{N 2} S_{N K}^{2}\right] \\
& \bar{\lambda}_{N i} \bar{S}_{N j}^{k}=\left(\lambda_{N 1} S_{N L}^{1}+\lambda_{N 2} S_{N L}^{2}+\lambda_{N 2} S_{N K}^{2} \theta_{L 1}\right)>0 \\
& A_{3}=\left(\frac{1}{|\theta|}\right)\left[\left(\theta_{K 3}+\theta_{23} \theta_{K 2}\right)\left(S_{K L}^{2} \theta_{N 1}-S_{K N}^{2} \theta_{L 1}\right) \lambda_{K 2}-\theta_{23}\left(\theta_{L 1} \theta_{N 2}-\theta_{N 1} \theta_{L 2}\right) \bar{\lambda}_{K i} \bar{S}_{K j}^{k}\right] \\
& \bar{\lambda}_{K i} \bar{S}_{K j}^{k}=\left[\lambda_{K 2}\left(S_{K L}^{2}+S_{K N}^{2}\right)+\lambda_{K 3} S_{K L}^{3}\right]>0 \\
|\lambda|= & \left(\lambda_{L 1} \lambda_{N 2}-\lambda_{L 2} \lambda_{N 1}\right)<0 \\
A_{1}= & \left(\frac{1}{|\theta|}\right)\left[\theta_{K 3}\left(\lambda_{L 1} S_{L N}^{1}+\lambda_{L 2} S_{L N}^{2}\right)-\theta_{N 1} \theta_{K 3}\left(1-\lambda_{L 3}\right)-\theta_{23}\left(\theta_{L 1} \theta_{N 2}-\theta_{N 1} \theta_{L 2}\right) \tilde{\lambda}_{L 3} S_{L K}^{3}\right]<0 \\
A_{2}= & \left(\frac{1}{|\theta|}\right)\left[\theta_{K 3}\left(\lambda_{N 1} S_{N L}^{1}+\lambda_{N 2} S_{N L}^{2}\right)\right]<0 \\
A_{3}= & \left(\frac{S_{K L}^{3}}{|\theta|}\right)\left[\theta_{N 1}\left(\theta_{K 3}+\theta_{23} \theta_{K 2}\right)-\left\{\left(\theta_{23} / \theta_{K 3}\right)|\theta|-\theta_{N 1} \theta_{L 2}\right\}\right]<0
\end{aligned}
$$

